INDEPENDENT JOURNAL OF MANAGEMENT \& PRODUCTION (IJM\&P)

http://www.ijmp.jor.br

v. 6, n. 2, April - June 2015

ISSN: 2236-269X

DOI: 10.14807/ijmp.v6i2.256

\title{
MUSIC PRODUCTION-CONSUMPTION AND THE SERVICE-GOOD SPECTRUM UNDER THE SWAY OF A SHIFT WITHIN A SHIFT
}

Sílvia Helena Meyer Carvalho

Federal University of Rio Grande do Sul, Brazil

E-mail: shmeycar@gmail.com

Annibal Scavarda Federal University of the State of Rio de Janeiro, Brazil E-mail: annibal.scavarda@unirio.br

Submission: $30 / 07 / 2014$

Revision: 13/08/2014

Accept: 08/11/2014

\section{ABSTRACT}

Nowadays music constitutes a phenomenon whose complexion entangles aspects simultaneously related to society, culture, art, business, and technology. Due to the combined influence of these aspects, music production-consumption acquires some unique features. Added to that, the swift evolution and growing influence of the economic-technological association have increasingly affected music as a sociocultural phenomenon, as an art form, and as a corporate business, increasing the complexity of an already convoluted context. Given the composite and dynamic constitution of the music field, the present approach departs from an interdisciplinary analysis, establishing a methodological groundwork that comprehends conceptual and qualitative research, elaborated through exploratory study.

Under a standard economic perspective, music productionconsumption belongs in the structure of the music supply chain, presenting a rather uncertain status between service and good. Apart from the economic understanding, however, music comprises a wide variety of manifestations, which do not suit conventional productionconsumption processes. In order to cope with the inexorable duality of this paradoxical coexistence, this study proposes a model intended to 
contribute to the building of a comprehensive knowledge on music production and consumption.

As this model departs from some specific flows of music production and consumption, it creates an array of patterns, pinpointing their situation within the service-good spectrum. In addition, it considers Digital Revolution and globalised communications as enablers that affect the foundations of traditional music, unbalance routine flows inside the supply chain of the music industry, and cause music production-consumption relationships to shift their status from good-oriented to service-oriented.

Keywords: Music, Supply chain management, Services management, Technology, Digital revolution.

\section{INTRODUCTION}

Archaeological evidence suggests that the manufacture of bone and ivory flutes may have started more than 35,000 years ago (CONARD; MALINA; MÜNZEL, 2009). Because the musical practice associated to these instruments appears to have taken place in social gatherings of religious nature (MORLEY, 2009), it is possible to infer that music has emerged from circumstances that allowed the establishment of a primary sociocultural dimension. Due to its remote roots, this sociocultural dimension constitutes an ancestral heritage as old as music itself.

Nevertheless, there is more to music than just heritage. First and foremost, it has a strong tradition as an art form, which goes back to Ancient Greece, more than 2,500 years ago (BURKHOLDER; GROUT; PALISCA, 2010). Based upon this tradition, successive generations of scholarly approaches have addressed music as a means for emotional expression endowed with aesthetic sense (COOK; DIBBEN, 2010). The addition of an economic dimension is far more recent, but businesses related to music have existed at least since the sixteenth century (RAYNOR, 1972). Besides the aggregated artistic and economic dimensions of music, it is necessary to consider that the prehistoric manufacture of flutes was already employing Stone Age technology (CONARD; MALINA; MÜNZEL, 2009). Hence, a technological dimension has emerged together with sociocultural ancestry, long before music has become an activity of artistic or economic nature. In fact, it was around music technology that the artistic and the economic dimensions of music have found the necessary conditions 
to rise and evolve. On the one hand, as technology kept continuously contributing to the evolution of musical instruments, it has furnished a fertile substratum for the aggregation of artistic value to the musical practice. On the other hand, by the end of the nineteenth century, through the establishment of a strong alliance with the growing economic dimension, technology went beyond the condition of a vehicle for performance. In consequence, economy has gradually turned music into an industrial commodity, while technology has provided the means of production, distribution, and consumption of this industrialised music (MARTIN, 1997).

During the twentieth century, the association between the economic and technological dimensions has grown more powerful, exerting a pivotal influence upon the overall structure of the musical phenomenon. By reshaping sociocultural ancestry, overshadowing artistic tradition (GOODRICH; RENARD; ROSSITER, 2011), and favouring the profitable production of music as a commodity, the economic-technological association has enabled the rise of a particularly powerful industry, which, for about one hundred years, was the core of music economy (STOLBA, 1990). This shift in balance has taken the musical phenomenon from a perspective mostly relied upon sociocultural and artistic practices to the condition of a techno-business. Amidst the most paradoxical commonality established since the emergence of music, a powerful corporate business has turned an otherwise intangible art from into a high-tech product capable to generate revenues in the house of billions (RENARD, 2010).

Nonetheless, the same economic-technological influence kept following the twentieth-first century trends of Digital Revolution and globalised communications, necessarily affecting routine flows of production and consumption established inside the supply chain of the centenary music industry (IFPI, 2012). This evolutionary outcome has created a shift within a shift, increasing the influential power of the technological dimension, which, by becoming a double-edged sword, at the same time, magnified the power and complexity of the music industry, as well as challenged its senior structure (GRAHAM et al., 2004). Other than that, new technologies keep affecting the entire structure of music, turning the sociocultural, artistic, and economic dimensions even more complexly attached to each other. 
The influence of technology upon the evolution of music has been anything but subtle. In the role of a critical enabler, the technological dimension has continuously contributed to the development of music as a sociocultural phenomenon, as an art form, and as an economic activity. Thus, if the twentieth century economictechnological association has imposed production-consumption relationships upon music and the twentieth-first century technology alone has swiftly reshaped these same relationships, this did not represent a momentary or isolated event. Given the axial function of technology in the rise of music and across the millenary evolution of its four-dimensional structure, there is no reason to believe that towards the future this influence will tend do decrease. Consequently, in face of a new technological order, to change and to adapt are more than desirable, becoming indeed a matter of survival for the art of music as much as for the music business. After all, it was by means of technology that, in less than one hundred years, the age-old phenomenon of music has gone from production-consumption circles confined to specific sociocultural and geographical contexts to a broad network of channels, which enable any performance to gain the world at the speed of a mouse click.

Based upon this evolutionary pathway, it is possible to consider that nowadays music production-consumption relationships entail ancestry, tradition, technology, and entrepreneurship in a broad, as well as dynamic set of exchanges that may occur anywhere within the service-good spectrum. The different flows through which these exchanges come about constitute music production and consumption patterns. In other words, production and consumption patterns are means to the establishment of music production-consumption relationships.

Departing from the analysis of flows, patterns, and relationships through which music production-consumption takes place, the present study unfolds into six sections. To the introductory section, follow a brief analysis of the literature on the subject of music production-consumption and the methodology, which comprises the research approach, processes, questions, and aims. The fourth section proposes a revision of the production-consumption concept, so that it may conform to the full body of dimensions encompassed by the contemporary musical phenomenon. The following section establishes a categorisation of music production and consumption patterns, identifying the different flows through which these patterns come about. The last section brings out the concluding considerations on music production and 
DOI: 10.14807/ijmp.v6i2.256

consumption, regarding the specific flows, patterns, and relationships they enable, their particular status quo within the service-good spectrum, and their prospective situation under the shift imposed by Digital Revolution.

\section{LITERATURE REVIEW}

It is not the purpose of the present study to provide a thorough revision of the scholarly literature on the subject of music production-consumption. However, in order to show how different approaches deal with it, Table 1 arranges a specific set of sources according to their thematic emphases on eleven selected topics related to music production-consumption and Table 2 shows how these emphases concentrate around the same topics.

Table 1: Thematic emphases on topics related to music production-consumption under distinct perspectives

\begin{tabular}{|c|c|c|c|c|c|c|c|c|c|c|c|c|}
\hline & Analysed sources & 1 & 2 & 3 & 4 & 5 & 6 & 7 & 8 & 9 & 10 & 11 \\
\hline \multirow{4}{*}{ A } & PRESTES FILHO, 2005 & CE & SE & & SE & CE & & & CE & $\mathrm{CE}$ & & SE \\
\hline & GRAHAM et al., 2004 & CE & $\mathrm{IM}$ & & CE & CE & & & CE & $\mathrm{CE}$ & & \\
\hline & THROSBY, 2002 & CE & SE & $\mathrm{IM}$ & CE & CE & & & $\mathrm{CE}$ & CE & & SE \\
\hline & ALEXANDER, 1994 & CE & $\mathrm{IM}$ & & SE & CE & & & CE & CE & & \\
\hline \multirow{5}{*}{ B } & HERSCHMANN, 2010 & CE & $\mathrm{CE}$ & & CE & CE & & & $\mathrm{CE}$ & CE & & SE \\
\hline & BENHAMOU, 2007 & CE & $\mathrm{CE}$ & SE & SE & CE & & & $\mathrm{CE}$ & SE & CE & $\mathrm{IM}$ \\
\hline & JONES, 2000 & CE & $\mathrm{CE}$ & SE & SE & CE & & & $\mathrm{CE}$ & & & \\
\hline & ADLER, 1985 & CE & $\mathrm{CE}$ & & & & & & $\mathrm{CE}$ & $\mathrm{IM}$ & & IM \\
\hline & ROSEN, 1981 & $\mathrm{CE}$ & $\mathrm{CE}$ & & & $\mathrm{IM}$ & & & $\mathrm{CE}$ & $\mathrm{IM}$ & SE & $\mathrm{IM}$ \\
\hline \multirow{5}{*}{ C } & KRIMS, 2007 & SE & $\mathrm{CE}$ & SE & IM & & & & $\mathrm{CE}$ & SE & SE & \\
\hline & MARTIN, 1997 & $\mathrm{IM}$ & CE & SE & IM & SE & IM & IM & CE & CE & CE & \\
\hline & NEGUS, 1996 & $\mathrm{IM}$ & CE & SE & IM & SE & & IM & CE & $\mathrm{CE}$ & & \\
\hline & GENDRON, 1986 & IM & CE & SE & IM & SE & & IM & CE & CE & & \\
\hline & RAYNOR, 1972 & $\mathrm{IM}$ & $\mathrm{CE}$ & SE & & SE & $\mathrm{IM}$ & $\mathrm{IM}$ & $\mathrm{CE}$ & $\mathrm{IM}$ & $\mathrm{CE}$ & $\mathrm{IM}$ \\
\hline \multirow{3}{*}{ D } & $\begin{array}{l}\text { BURKHOLDER; GROUT; } \\
\text { PALISCA, } 2010\end{array}$ & IM & SE & CE & IM & SE & IM & IM & $\mathrm{IM}$ & SE & CE & \\
\hline & DOWNS, 1992 & IM & SE & CE & & SE & IM & IM & $\mathrm{IM}$ & & CE & \\
\hline & STOLBA, 1990 & IM & SE & CE & IM & SE & IM & IM & $\mathrm{IM}$ & $\mathrm{IM}$ & CE & \\
\hline
\end{tabular}

Selected topics:

1. Music productionconsumption as an economic issue

2. Music productionconsumption as a sociocultural issue

3. Music productionconsumption as an artistic issue
4. Music production-consumption within the service-good spectrum

5. The shifting impact of technology over the last 150 years

6. Technology as an axial influence

7. Artistry as a traditional influence
8. Commercial music

9. Popular music

10. Art music

11. Low profile musical activities

Level of emphasis in the approach of topics on music production-consumption CE Central $\quad$ SE Secondary IM Implied $\square$ Unaddressed 
Group A contains sources whose primary focus addresses music productionconsumption as an economic issue associated with the practices of popularcommercial music and with the shifting impact of technology over the last 150 years. Sources in this group also devote some considerable attention to music productionconsumption within the service-good spectrum. Keeping some similarity with the thematic emphasis of group A, group B addresses music production-consumption as an economic and sociocultural issue associated to commercial music. In groups $\mathrm{C}$ and $\mathrm{D}$, on the other hand, the sources respectively target music productionconsumption as sociocultural issue associated with commercial music or as an artistic issue associated with the practice of art music.

Table 2: Quantitative and qualitative analysis of the topics on music production-consumption in relation to the sources considered in Table 1.

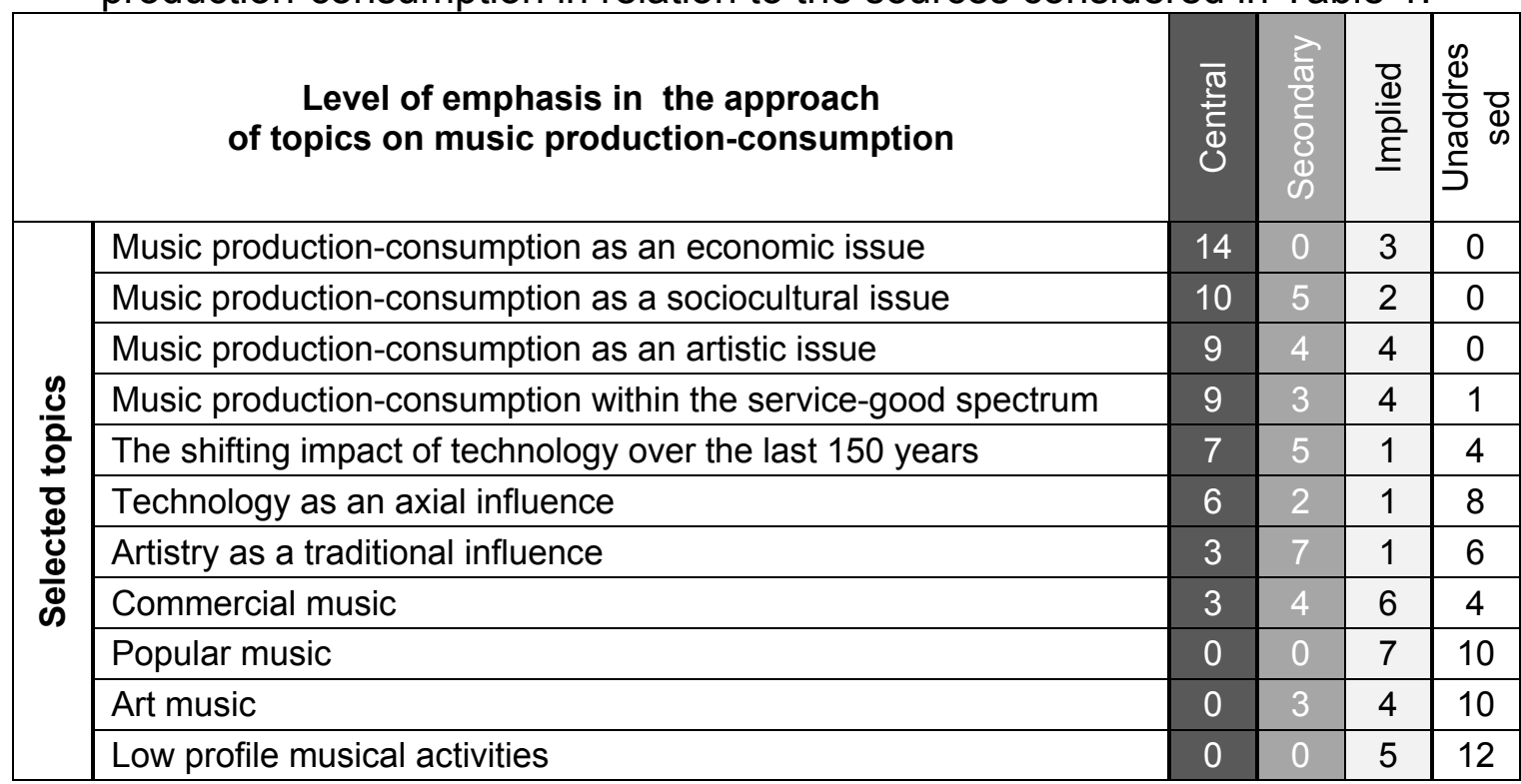

In a general appraisal, the considered sources tend to show higher interest for commercial and popular music than for art music or for the low profile musical activities. Other than that, they balance economic, sociocultural, and artistic issues related to music production-consumption in two different ways. While a great number of the approaches tend to favour economic and/or sociocultural issues at the expense of the artistic aspect necessarily associated to the musical practice, the approaches that devote more attention to the artistic issues tend to overlook the economic aspect of music production-consumption. 
With regard to the way the sources concentrate their emphases around the selected topics, Table 2 shows that most of them have thematic emphasis centred on sociocultural and economic aspects of commercial music. In an inverse situation, music production-consumption under the axial influence of technology, under the traditional influence of artistry, or in relation to the low profile musical activities, constitute topics of lesser interest, which, besides remaining unaddressed in most of the considered sources, do not constitute the central emphasis in any of them.

This analysis indicates that, as a set, these literature sources show music production-consumption in a broader perspective. Nevertheless, each group tends to underestimate some key aspects of a thorough understanding on this particular subject. Groups A and B, for instance, almost do not take the artistic component of the musical practice into consideration, whereas groups $C$ and $D$ tend to neglect the low profile musical activities. Moreover, none of the groups directly addresses the axial influence of technology or the traditional influence of artistry upon music production-consumption. In face of this perspective, the present study proposes a more nuanced understanding of music as worldwide phenomenon of sociocultural nature, as a traditional artistic craft, as a profitable economic activity, and as a millenary substratum for the employment of new technologies.

\section{METHODOLOGY}

Given the complex configuration of music in general (NEGUS, 1996), this study has departed from an interdisciplinary approach that brings together the efforts of researchers in the fields of Music and Production Engineering. The collaborative work of these researchers proposes a spiralling approach (BERG; LUNE, 2004) intended to the pursuit of a broader knowledge on music. By building up around sociocultural, artistic, and technological aspects of the musical phenomenon as a profitable segment of the economic activity, this knowledge should subsidise the development of a supply chain model that meets the universe of manifestations, technologies, institutions, organisations, and relationships involved in different levels of the musical practice.

In order to consider the contemporary musical phenomenon in its multiple features (HERSCHMANN, 2010), the overall plan of this study group establishes a fundamental research elaborated by means of triangulation and developed through 
different stages, each of them involving some specific strategies. The first stage has comprised collection, analysis, and systematisation of information regarding the complexion of music economy. The present study reflects the results of this prospection stage, whose methodological framework has involved literature review, associated with historical and theoretical analysis, as the foundations of a qualitative and conceptual research elaborated through exploratory study on topics directly or indirectly associated to music production-consumption.

The general goal of this research is to contribute to the knowledge on music as a phenomenon of sociocultural, artistic, and economic nature that also furnishes a singular substratum to the employment of new technologies. At an intermediary level, this knowledge should support the analysis of the interrelations between the economic segments, professional activities, production-consumption flows, and technologies involved in the constitution of the music supply chain (PRESTES FILHO, 2005). At the specific level, the goal of this study is to develop a thorough approach on music production-consumption within the service-good spectrum, postulating that it might take place in an extended range of performance and appreciation contexts, besides comprising different levels of commercial intent (BENHAMOU, 2007).

The simultaneous interactions among sociocultural, artistic, economic, and technological dimensions of music production-consumption turn the analysis of this subject into a rather challenging task. This may be the reason why literature tends to emphasise some aspects at the expense of others (see Table 1 and Table 2). In that sense, the sources centred on music business, music industry, as well as on music and technology, tend to deal more specifically with issues related to the record industry, the show business, and the star system. Sources on music sociology or on music history, on the other hand, have an inherent inclination towards the sociocultural and/or artistic aspects of music production-consumption.

Hence, the crosschecking of information gathered from the sources considered in the second section with additional data on the archaeology, philosophy, and aesthetics of music gives rise to the questions that ground the present study. How is it possible for the intangible art of music to have become, as well, a production-consumption object? Given that the production and/or 
consumption of low profile musical activities may occur in non-commercial basis, do these activities have a true economic role? If technology constitutes an evolutionary axis around which the sociocultural, artistic, and economic dimensions of the musical practice have grown intermingled with each other, how does Digital Revolution, in association with globalised communications, affect the understanding of music as a production-consumption object? Once economy and technology have imposed production-consumption relationships upon music, where do these relationships stand with regard to the service-good spectrum of the music supply chain?

\section{MUSIC PRODUCTION-CONSUMPTION}

According to Negus (1996), the modus operandi of the productionconsumption binomial in music tends to be indefinite and subject to different interpretations. Taking into account the impressive figures of the corporate music business in terms of record sales, box office revenues, or personal earnings (GRAHAM et al., 2004), the existence of standard music production-consumption relationships is hardly inconspicuous. However, they are far less noticeable in the case of traditional art music, like the symphony, the opera, or the ballet, and become even inadequate if applied to the low profile musical life that fills the gap between mass music and art music. The reason behind these antagonistic understandings relates to the fact that orthodox views generally overlook the wide diversity of musical manifestations and the intricate set of dynamics encompassed by the fourdimensional structure of music. The regular manufacture-distribution-sales-purchase process, for instance, applies to the supply chain of most commodities as much as to the record industry. Nonetheless, it does not fit the notion of music as an intangible art form (NEGUS, 1996). Conversely, a view centred in the aesthetic understanding of music as a pure art meant to convey emotional expression disregards a great number of profit-oriented musical manifestations, as well as the fact that music provides an actual means of subsistence for countless people around the world. With that in mind, the present study proposes a model in which music productionconsumption relationships combine economic and aesthetic understandings of music, bringing them closer to each other (BENHAMOU, 2007).

As pointed by Adler (1985), after Rosen (1981), music allows the combination of the supply chain related binominal production-consumption to the aesthetic 
binominal performance-appreciation. Under this perspective, it is possible to consider the moment of performance as a production process, whereas the appreciation of this performance corresponds to the associated consumption (Figure 1). The production agents are the musicians, who create/produce the performance, whereas the consumers are any appreciative audiences, which would like to invest time and/or money on it (ADLER, 1985). At this level, music production-consumption may occur anywhere within the service-good spectrum and cohere with the physical retail purchase of material recordings as much as with the intangible experience that, according to Herschmann (2010), belongs to the realm of spectacle.

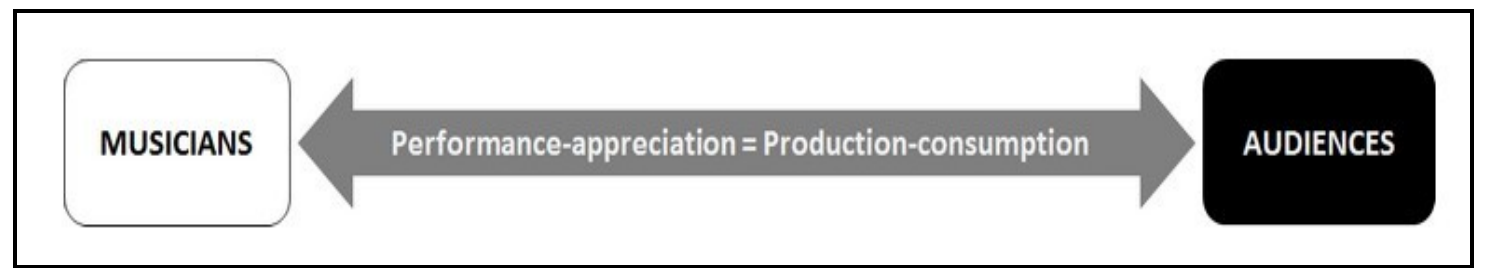

Figure 1: The association between music performance-appreciation and music production-consumption

The virtue of this model is to harmonise with the complex set of music sociocultural, artistic, economic, and technological dimensions. Moreover, it suits any musical manifestations, regardless of value judgment concerning differentials, like the nature of the approach, the degree of profit intent, the level of artistry, or the areas of expertise involved in the performance-appreciation context.

\section{MUSIC PRODUCTION AND CONSUMPTION PATTERNS}

Once the performance-appreciation mechanism brings about some specific music production and consumption flows, it constitutes different patterns, which establish the full body of music production-consumption relationships. For study purposes, the present analysis establishes three basic sets of music production and consumption patterns. As shown in Figure 2, each of these patterns comprises some particular flows. 


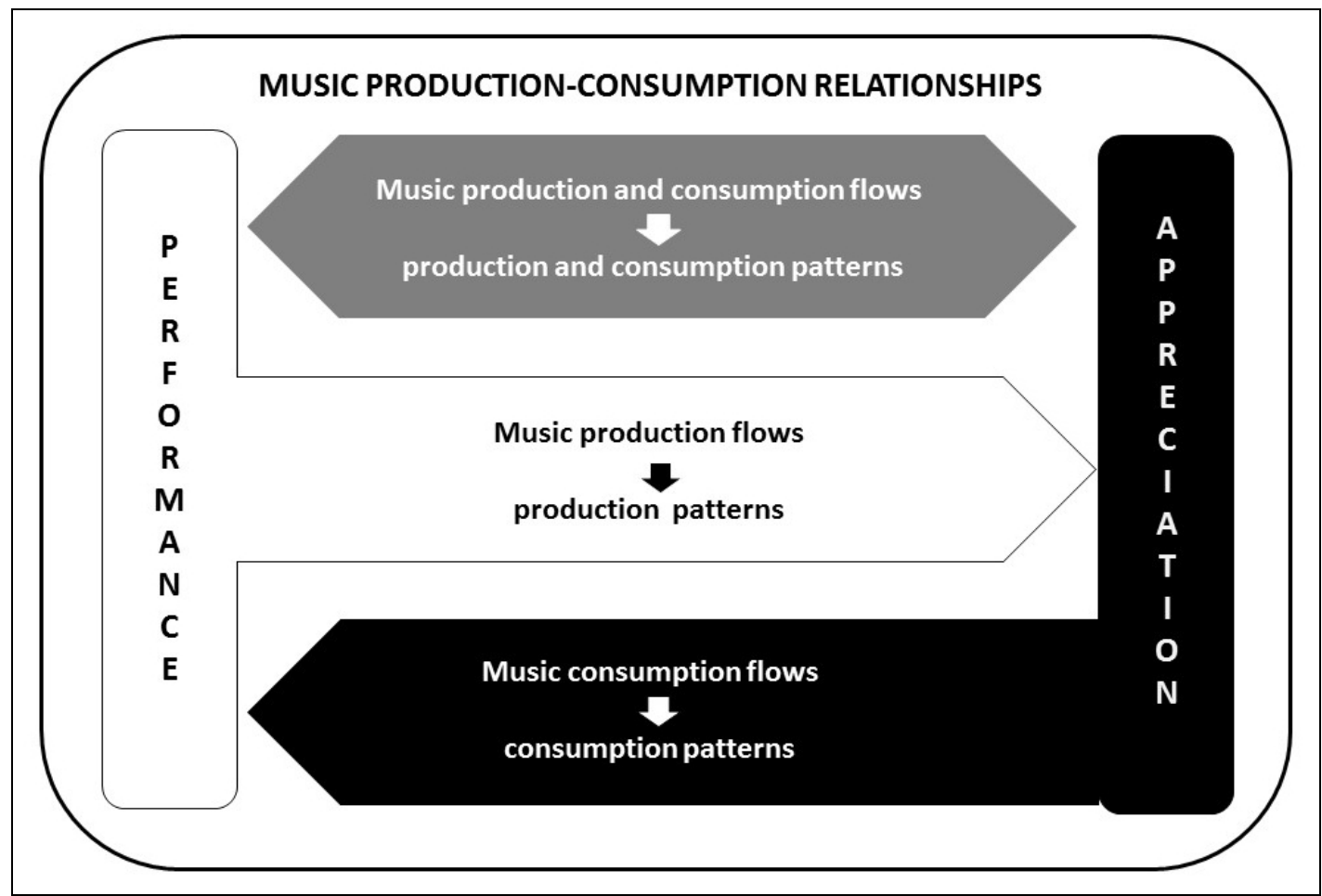

Figure 2: Music production-consumption relationships

Production-consumption patterns embody binary flows where performance and appreciation develop interdependent associations. The flows where performance or appreciation occur in an isolated and independent state establish either production or consumption patterns. Further extending the level of detail, each of the three basic sets also entails dichotomous categories and sub-categories of music production and/or consumption patterns (Figure 3).

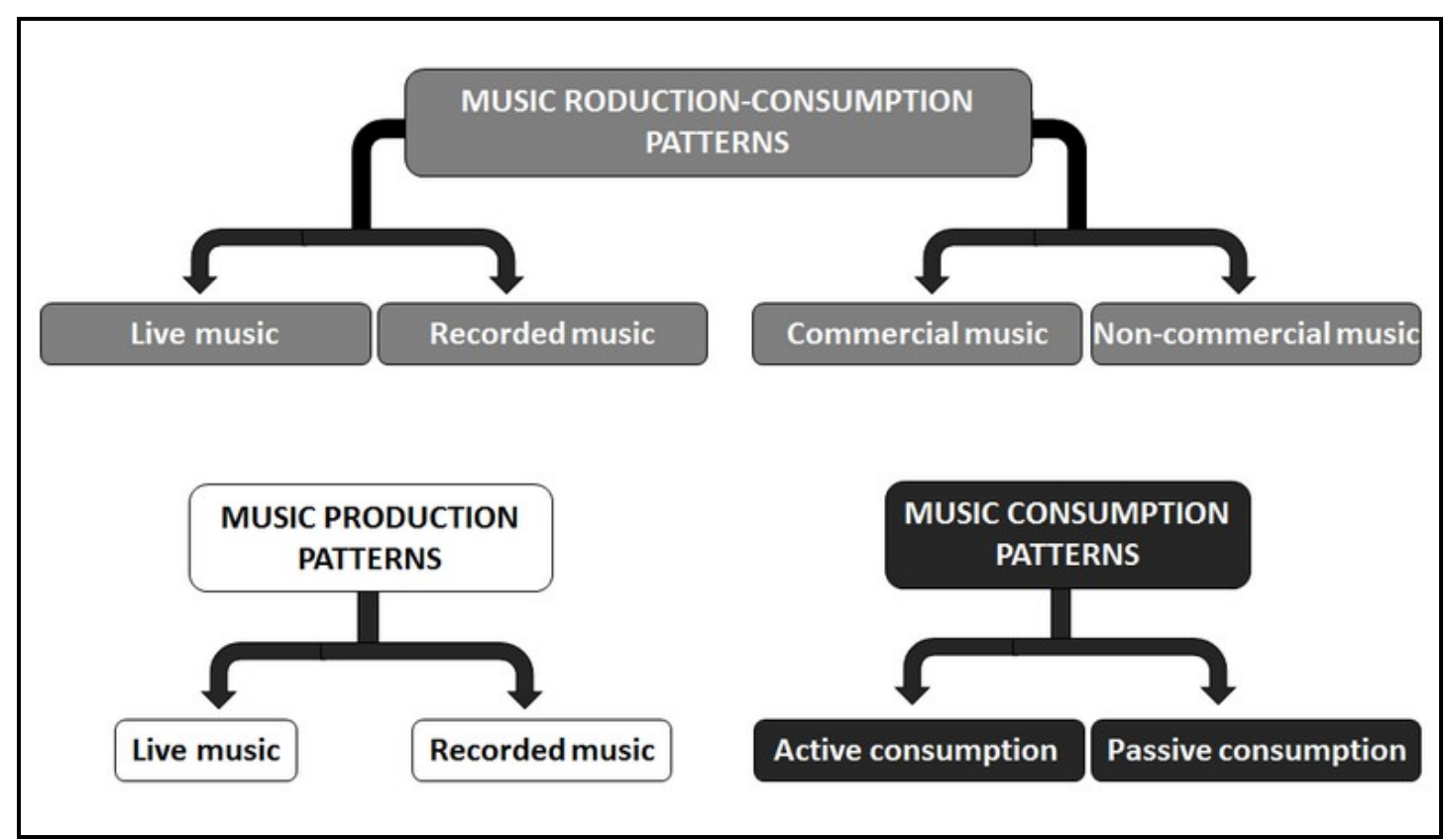

Figure 3: Music production and consumption patterns 


\subsection{Production-consumption Patterns}

To the first dichotomy of production-consumption patterns belong the categories of live or recorded music. Live music relates to a situation where musicians and audiences share the production-consumption process within a single moment, so that, performance/production and appreciation/consumption have a simultaneous and momentary influence upon each other. Conversely, recorded music captures a moment of performance/production, for future appreciation/consumption at a different time and place.

As live music alchemises the moment of performance-appreciation into an entire production-consumption cycle, the integral components of this cycle have direct, momentary, and immediate influence upon one another. This way, live music keeps the production-consumption relationships restricted to the service zone of the spectrum and may even further extend the immaterial quality of the performanceappreciation mechanism to the level of experience (HERSCHMANN, 2010).

Given that live music only requires simultaneous production and consumption, any performance fits this category, regardless of other qualifying criteria, like the artistry level, the degree of profit intent, or the audiences' watching/purchasing investment. However, as mass communications media enable worldwide broadcast of any performance moment, technology, may reshape some aspects of the production-consumption cycle comprised in live music. The first of them is the size of the audience that increases upon the influence of communications media (ROSEN, 1981) and expands at exponential rates, under the sway of Digital Revolution. A negative outcome of live broadcast is the absence of an immediate interaction between performers and audiences, preventing a real time influence of the production-consumption cycle components upon one another in this particular context. In addition, live broadcast also reduces the inherent service-experience quality of this pattern.

In the category of recorded music, the performance-appreciation mechanism abandons the immaterial quality and makes use of the same production-consumption standards of most regular commodities. This materialisation ensues from a fast evolution of technologies destined to capture, perpetuate, and reproduce sound that has begun with the emergence of the phonograph in the late 1800 s, ultimately 
enabling the storage of any musical performance for prospective consumption (ALEXANDER, 1994). As a milestone in the human conquest of sound, the twentieth century saw the rise of music in the physical forms of vinyl records, cassette tapes, Compact Disks (CDs), and Digital Versatile Discs (DVDs). By means of these physical forms, music became subject of industrial production and retail consumption like any regular commodity (MARTIN, 1997)

When, by the last decades of the twentieth century, the industrialisation process led music to compression, this has rather represented a technological step forward than the end of an evolutionary line. Primarily intended for storage in CDs and DVDs, compressed recordings have swiftly adjusted to the possibilities of the rising World Wide Web (WWW). For the sake of this adjustment, music begun to migrate from physical forms to simple information bites (RENARD, 2010) that could travel the world, in a matter of seconds. Therefore, in a time span of little more than one hundred years, recorded music went from industrialisation to virtualisation, i.e., from physical forms to a myriad of virtual formats. As this radical shift has changed the proportions of physical and virtual goods involved in music productionconsumption relationships, it has also affected some senior bonds between the centenary music industry and its familiar supply chain (ALEXANDER, 1994).

The rise of virtual music, combined to the extraordinary growth of globalised communications, has opened several new conduits for music exchange, download, and streaming at costs that could go as low as zero (THROSBY, 2002). In that sense, peer to peer, netlabels, commercial portals, online collections and radios, podcasting, artists' blogs and sites, among others, have brought about changes that reshaped recorded music flows around the world (PRESTES FILHO, 2005). The impact of these technologies upon the music supply chain has shaken physical distribution, shifting regular industrial production and retail consumption of music towards some intermediary point between service and good (JONES, 2000). Nonetheless, as this virtualisation keeps in constant progress, it may affect recorded music production-consumption standards in ways not yet fully predictable.

Once the basic premise of recorded music is to keep a performance moment in storage for future appreciation by consuming audiences that do not enter in direct contact with the production process, it does not make any distinctions regarding 
aspects like quality, means, or costs. However, the employment of distinct recording and reproduction technologies may affect the situation of this particular category within the service-good spectrum.

The second dichotomy of music production-consumption patterns comprises the categories of commercial and non-commercial music. Regardless of profit intent or financial investment, both categories equally comply with the performanceappreciation mechanism. The differentiation between them regards the commercial intent of the performance, as well as the financial investment required for the appreciation. In that sense, commercial music applies to contexts where the performance/production has commercial intent and the associated appreciation/consumption requires financial investment. Consequently, noncommercial music should imply a performance/production situation with no commercial intent, whose appreciation/consumption does not require financial investment.

From a strictly pecuniary understanding, the production of music is rarely devoid of any commercial purpose, whereas its consumption may not necessarily depend on an appreciative investment other than time. After all, it is neither logical nor fair to assume that, even if appreciation happens without requiring audience's investment, the performance takes place in the absence of any profit intent. In fact, costless appreciation quite often depends on government subventions and/or patronage, which enable the performance to have purposes other than box-office or record sales revenues. Production-consumption relationships of this nature occur, for instance, in academic, historical, religious, and many other alternative contexts of performance-appreciation. In most of these cases, however, the fact that the audiences do not have to make a direct appreciation investment does not imply that the musicians did not receive any payment in return for their performance or that this performance did not generate financial expenses of any kind.

Thus, the distinction between commercial and non-commercial music depends on the balance between the performance financial support and the associated appreciative investment. In that sense, an authentic commercial music productionconsumption pattern involves revenue-oriented performances, generally undertaken by means of private corporate support, which require appreciative investment. In the 
opposite situation is the non-commercial music production-consumption pattern, comprising performances with no revenue intent that, due to financial support from government subventions and/or patronage, may allow costless appreciation. Once the nature of the financial support and the degree of the appreciative investment constitute flexible parameters, commercial and non-commercial music go beyond a single dichotomy. Depending on the way the financial support and the appreciative investment balance each other out, they may establish an actual gamut in between the two straightforward patterns of commercial and non-commercial music production-consumption. Added to that, the material quality of the performanceappreciation mechanism across this gamut also ranges from the service-experience quality of live music to the standard industrial processes encompassed by the production and consumption of recorded music in physical forms.

\subsection{Production Patterns}

This set of patterns dichotomises in the categories of art music and popular music production, each of them oriented towards specific appreciative audiences. While the former targets audiences from a rather strict sociocultural stratum (KRIMS, 2007), the latter usually aims at wider clienteles or even at mass consumption (MARTIN, 1997). Given that popular music production usually has wider consumption niches, it becomes more attractive to corporate investment (MARTIN, 1997). Art music, on the other hand, tends to compensate its lower productivity rates by means of a financial support that combines government subventions and patronage (BENHAMOU, 2007). Although the two categories have quite antagonistic consumer basis, both of them may still share some appreciative audiences, especially when considering that current times allow different musical choices for different daily life situations (BURKHOLDER; GROUT; PALISCA, 2010). However, regardless of the specific clientele, the material quality of the performance-appreciation mechanism in each of these production patterns may establish a range of possibilities as wide as that comprised across the gamut of commercial and non-commercial music.

\subsection{Consumption Patterns}

Once the appreciative-consumption of music does not require more than the audiences' sensorial exposition to any performance, the range of possibilities through which it may come about is extremely wide. Moreover, as aural absorption does not 
depend on any voluntary action, most people do not enjoy the privilege of not listening. Due to this condition, music appreciation may happen upon audiences' choice, as well as by compulsory aural absorption, yielding the dichotomous categorisation of active and passive consumption.

The active consumption pattern applies to situations where audiences choose to appreciate the music performed by specific artists, in specific genres, styles, or artistic approaches, under specific performance-appreciation circumstances. The choice parameters either represent individual options (GENDRON, 1986) or rise from a collective influence, depending on a number of aspects, like the required time and/or money investment (ADLER, 1985), as well as other motivations that may range from high cultural interest to a simple search for entertainment. Additionally, as Digital Revolution and globalised communications are able to make appreciative investments go as low as zero, new consuming behaviours tend to favour virtual formats over physical forms, ultimately reshaping some routine flows of the music supply chain (JONES, 2000). With regard to the material quality of the appreciation, active consumption choices also rely upon flexible parameters. Therefore, they may happen at any point between the service-experience and the physical purchase of goods.

Given that the opposite consumption pattern tends to happen in close connection with the acoustically crowded soundscape provided by urban society, involuntary aural exposition to music may even stand comparison to its voluntary counterpart. As life in an urban context necessarily implies compulsory exposition to musical backgrounds (KRIMS, 2007), the sizable presence of music mingled to other contexts may most often go unnoticed. Besides comprising an urban phenomenon of considerable proportions, passive music consumption belongs in a very complex set of circumstances. This complexity allows the establishment of a sub-dichotomisation, according to the specific environment in which the involuntary exposition to music takes place. The first sub-category relates to passive music consumption of artistic nature, which takes place in association with artistic contexts, like general dramaturgy and ballet. The extra-artistic passive consumption, on the other hand, may happen in any spheres of communications media or in any social situations outside an artistic context, e.g., nightspots, street publicity, and sound systems at different public spaces (KRIMS, 2007). However, regardless of contextual nature, the 
background status of both sub-categories does not enable material appreciation, restricting the entire set of passive music consumption patterns to a serviceexperience condition.

\subsection{Cumulative Patterns}

Although the theoretical analysis of music production and consumption flows suggests the establishment of different sets, categories, and sub-categories of patterns, in actual production-consumption relationships these patterns never occur isolated from each other. They have, indeed, a strong tendency to accumulate. This accumulation usually involves live or recorded music as fundamental patterns around which the others aggregate. A given live performance may, for instance, come about under private corporate support, target active mass consumption, and require appreciative investment. These circumstances allow a single live music situation to aggregate, as well, the patterns of commercial music production-consumption and popular music production intended for active consumption.

The aggregating flexibility of cumulative patterns expands the variety of music production-consumption relationships at exponential rates. In consequence, these relationships not only may occur anywhere within the service-good spectrum, but may also cross it from one end to the other. This happens, for instance, when a performance recorded live goes from a service-experience condition into a physical form, whose production-consumption relies on industrial manufacture and retail purchase like any regular commodity. Besides that, as current technology represents an ever-evolving enabler, cumulative association gradually acquires more potential to inflict significant shifts upon other patterns. Given the fact that nowadays even garage bands' performances may reach the streaming channels, the fusion of noncommercial and stored music production patterns becomes potentially promising (CREATIVE COMMONS, 2009). Once technology evolution keeps constantly deflecting and changing standard music production and consumption flows, cumulative patterns may very well create alternative strategies to bypass some traditional pathways of the old-fashioned music industry.

\section{CONCLUSIONS}

Music has emerged as a prehistoric sociocultural phenomenon closely related to the employment of lithic technologies (CONARD; MALINA; MÜNZEL, 2009). Over 
time, the influence of technology upon music has grown progressively stronger (GOODRICH; RENARD; ROSSITER, 2011). Added to that, as rationalism and industrialisation have boosted the economic activity of the 1900s, they promoted an economic-technological association that has not been idle to surpass the sociocultural heritage, as much as the artistic tradition of music. This particular shift has set the course of a fast evolution that took the intangible art form of music in connection with the great world of business and into the production lines (MARTIN, 1997). Together, the economic dimension, emerged from entrepreneurship (DOWNS, 1992) and the technological dimension, developed since the very origins of the musical phenomenon (CONARD; MALINA, 2008), gave rise to a branch of music rather strictly focused upon the high profit, high tech, and high profile musical practice (ROSEN, 1981). This way, the impact of a first economic-technological shift has induced the commoditisation of music, which has gradually aggregated production-consumption routines to its otherwise intangible condition as an art form.

Nonetheless, as music goes far beyond the techno-business or the spotlighted scenario, neither its four-dimensional configuration nor its widely varied set of manifestations are entirely suitable to the manufacture-distribution-sales-purchase processes that have brought industrially produced music to the level of a regular commodity. In order to meet the inherent uniqueness and diversity of music, the present study has proposed a production-consumption model that recognises musical performance as the production process, while the corresponding appreciation constitutes the consumption vehicle (ADLER, 1985). By applying with no restrictions to all music dimensions and to any musical manifestations, this model unveils a wide range of music production-consumption relationships established with or without commercial intent. Moreover, this perspective legitimises the economic grounds of practices target-oriented to ends other than box-office or record sales revenues, disclosing some intricate depths underneath the apparent straightforwardness that typifies the supply chain of industrialised music. In that sense, this model not only creates room for the recognition of music productionconsumption in association with activities that include low profile and/or amateurish practices, but also suggests further investigation of this particular branch of music economy. 
Under the influence of Digital Revolution and globalised communications, the performance-appreciation mechanism becomes broader and allows the situation of music production-consumption relationships within the service-good spectrum to be even more flexible. However, this same flexibility inflicts a second economictechnological shift to the very structure where these same relationships take place. The fast evolution of technology, especially during the second half of the twentieth century, stands as the vector of this shift.

Once technology has constituted an axial influence throughout the entire evolution of the musical practice, it had no trouble getting in tune with the economic dimension of music. The resulting economic-technological association has given rise to a consumption greed vicious cycle of Fordist inspiration that has played a pivotal role in the development of the music industry. For almost one hundred years, this circle has led to an increasingly greedy consumption of technological music as much as of musical technologies, ultimately taking the annual sales of the music industry to the house of billions (GRAHAM et al., 2004) and causing music technology to evolve at unprecedented rates. Nevertheless, by triggering successive technological advances, this high-speed evolution has also constantly challenged the music businesses. Forced to adapt, in order to survive, the corporate music industry kept feeding and reinventing the consumption greed cycle (MARTIN, 1997), up to the point where the resulting evolution of technology has enabled music to abandon physical forms in favour of a profuse variety of virtual formats (GRAHAM et al., 2004). As virtual formats combine nearly unlimited storage capacity with fast, far-reaching, and low cost distribution, they represent an almost unmatchable alternative to the old-fashioned standards of production-consumption that rely upon industrial manufacture intended for retail purchase. This way, the twentieth first century music industry witnesses the emergence of a shift within a shift, which, besides aggregating new flows to the music supply chain, also causes some regular productionconsumption relationships to change their status from product-oriented to serviceoriented.

Furthermore, as Digital Revolution and globalised communications allow online streaming, download, and exchange to create new production-consumption flows, they also may pull traditional flows off their usual courses. The dichotomy between commercial and non-commercial music production-consumption patterns, 
for instance, may well come to accommodate a third category, namely the noncommercial consumption of music produced with commercial intent, which already takes place in several virtual channels destined to the networking of individuals (CREATIVE COMMONS, 2009). Although the Digital Revolution potential to promote a deep reconfiguration of music production-consumption is not yet fully predictable, channels that connect individuals are already enabling the emergence of innovative flows. Thereupon, it is likely that low profile musical practices may eventually take advantage of these alternative media to sidestep senior meanders developed by the corporate star system (CREATIVE COMMONS, 2009). In fact, the chances of any shift in this direction to happen are actually closer to reality than to a visionary projection (IFPI, 2013). It is however necessary to keep in mind that in a context where giant mass communications businesses, like Google (1998), Facebook (2004), and Twitter (2006), rise and evolve at a frenetic pace, it becomes nearly impossible to make any accurate prediction on future mediatic potential to foster the sudden emergence of new production, distribution, and/or consumption mechanisms (ROEDY, 2011).

With regard to the situation of music production-consumption relationships within the service-good spectrum, at the current stage of this study, it is possible to maintain that they may range from immaterial performance-appreciation contexts to the industrial manufacture and retail purchase of physical recordings. Other than that, it is necessary to consider that the readily adaptive structure of the music supply chain, besides endowing production and consumption patterns with cumulative potential, also enables them to keep permanently changing, under the sway of a continuous technological evolution. Hence, the situation of music productionconsumption relationships within the service-good spectrum becomes as responsive to the impacts of media technology evolution as any other aspect related to the fourdimensional structure of music in general.

Finally, it is necessary to take into consideration that, as the perspective on the musical phenomenon goes beyond art or economy, music productionconsumption becomes wider and more complex. In addition to that, as the brisk evolution of technology, communications media, and society lessens the accuracy of any prognosis on music production and/or consumption, it also reinforces the need of an investigative monitoring on this particular subject. For both these reasons, further 
analysis and testing, besides helping to expand this study, may become instrumental in coping with the complexity of the musical phenomenon, as well as in keeping up with the swiftly changing structure of the music supply chain in the contemporary world.

\section{REFERENCES}

ADLER, M. (1985) Stardom and Talent. The American Economic Review, v. 75, n. 1 , p. $208-212$.

ALEXANDER, P. J. (1994) New Technology and Market Structure: Evidence from the Music Recording Industry. Journal of Cultural Economics, v. 18, n. 2 p. $113-123$. Retrieved from http://www.peterjalexander.com/images/New_Technology_and_Market_Structure.pdf Access: 02/01/14.

BENHAMOU, F. (2007) A Economia da Cultura, Translated by Souza, G. G.. Cotia-SP: Ateliê Editorial.

BERG, B. L.; LUNE, H. (2004). Qualitative Research Methods for the Social Sciences, v. 5. Boston: Pearson.

BURKHOLDER, J. P.; GROUT, D. J.; PALISCA, C. V. (2010) A History of Western Music. New York: WW Norton.

CONARD, N. J.; MALINA, M. (2008), New Evidence for the Origins of Music from Caves of the Swabian Jura, in: BOTH, A.A. et al. (Eds.), Orient-Archäologie, n. 22, p. 13 - 22. Retrieved from http://www.academia.edu/download/30927770/new_flutesconard-malina-muenzel-2009.pdf Access: 11/14/13.

CONARD, N. J.; MALINA, M.; MÜNZEL, S. C. (2009) New Flutes Document the Earliest Musical Tradition in Southwestern Germany. Nature, v. 460, n. 7256, p. 737 -740 . Retrieved from http://134.2.48.77/fileadmin/website/arbeitsbereich/ufg/urgeschichte_quartaeroekolog ie/publikationen/Conard_Malina_M_nzel_Flutes_Nature_2009.pdf. Access: 11/14/13.

COOK, N.; DIBBEN, N. (2010) Emotion in Culture and History, in: JUSLIN, P. N.; SLOBODA, J. A., (Eds.), Handbook of Music and Emotion: Theory, Research, Applications. Oxford University Press, p. $45-72$.

CREATIVE COMMONS (2009) Defining "Noncommercial” a Study of How the Online Population Understands "Noncommercial Use". Creative Commons Corporation: San Francisco, CA. Retrieved from http://mirrors.creativecommons.org/definingnoncommercial/Defining_Noncommercial_fullreport.pdf. Access: 12/04/11.

DOWNS, P. G., (1992) Classical Music: the Era of Haydn, Mozart, and Beethoven. New York: WW Norton.

GENDRON, B. (1986) Theodor Adorno Meets the Cadillacs, in: MODLESKI, T. (Ed.), Studies in Entertainment: Critical Approaches to Mass Culture. Indiana University Press, p. 18 - 36. Retrieved from http://users.ipfw.edu/tankel/pdf/gedron.pdf. Access: 02/02/14. 
GOODRICH, P.; RENARD, S.; ROSSITER, N. (2011) Social Network Analysis of the Music Industry: From Barrel Organ to Youtube. Retrieved from http://www.w.aabri.com/NC2011Manuscripts/NC11083.pdf. Access: 02/03/14.

GRAHAM, G. et al. (2004). The Transformation of the Music Industry Supply Chain: A Major Label Perspective. International Journal of Operations \& Production Management, v. 24, n. 11, p. 1087-1103.

Retrieved www.emeraldinsight.com/researchregister Access: 11/01/2013.

HERSCHMANN, M. (2010) Indústria da Música em Transição, São Paulo: Estação das letras e cores.

IFPI (2012) IFPI Digital Music Report 2012, London: IFPI. Retrieved from http://www.ifpi.org/content/section_resources/dmr2012.html Access: 01/29/14. IFPI (2013) An Industry on the Road to Recovery: Facts and Figures. IFPI Digital Music Report 2013, London. Retrieved from http://www.ifpi.org/content/section_resources/dmr2013.html. Access: 01/29/14.

JONES, S. (2000) Music and the Internet. Popular Music, v. 19, n. 2, p. $217-230$. Retrieved from http://journals.cambridge.org/PMU. Access: 02/02/14.

KRIMS, A. (2007) Music and Urban Geography. Routledge: Taylor and Francis Group: New York.

MARTIN, P. J. (1997) Sounds and Society: Themes in the Sociology of Music, Manchester University Press, Manchester.

MORLEY, I. (2009) Ritual and Music: Parallels and Practice, and the Paleolithic. Becoming Human: Innovation in Prehistoric Material and Spiritual Culture. Cambridge University Press, p. $159-175$.

NEGUS, K. (1997) Popular Music in Theory: An Introduction. Middletown, CT: Wesleyan University Press 243p.

PRESTES FILHO, L. C. (Coord.) (2005) Cadeia Produtiva da Economia da Música, Rio de Janeiro: Instituto Gênesis/ PUC-RJ.

RAYNOR, H. (1972), A Social History of Music: From the Middle Ages to Beethoven, London, Barrie \& Jenkins.

RENARD, S. (2010) Unbundling the Supply Chain for the International Music Industry. Manchester, New Hampshire, 2010. Doctor of Business Administration (D.B.A.) Dissertation - International Business, School of Business Southern New Hampshire University. Retrieved from http://academicarchive.snhu.edu/bitstream/handle/10474/474/int2010renard.pdf. Access: 02/01/2014.

ROEDY, B. (2011) What Makes Business Rock: Building the World's Largest Global Networks. Hoboken, NJ: John Wiley \& Sons, Inc.

ROSEN, S. (1981) The Economics of Superstars. The American economic review, v. 71, n. 5 , p. 845-858.

STOLBA, K. M. (1990) The Development of Western Music: A History, Dubuque, Wm. C. Brown Publishers.

TAGG, P. (1982) Analysing Popular Music: Theory, Method and Practice. Popular Music v. 2, n. 41, p. 37-67. 
DOI: 10.14807/ijmp.v6i2.256

THROSBY, D. (2002) The Music Industry in the New Millennium: Global and Local Perspectives. Global Alliance for Cultural Diversity. Paris: UNESCO-Division of Arts and Cultural Enterprise. Retrieved from

http://citeseerx.ist.psu.edu/viewdoc/download?doi=10.1.1.199.8085\&rep=rep1\&type= pdf. Access: 02/02/2014. 